\title{
NATURAL AND MAN-MADE FLOOD RISK MAPPING AND WARNING FOR SOCIALLY VULNERABLE POPULATIONS
}

\author{
D. MIOC ${ }^{1}$, J.N. NKHWANANA ${ }^{2}$, K.K. MOREIRI ${ }^{2}$, B. NICKERSON ${ }^{3}$, M. SANTOS 2 , E. MCGILLIVRAY ${ }^{4}$, \\ A. MORTON ${ }^{4}$, F. ANTON ${ }^{1}$, A. AHMAD 2 , M. MEZOUAGHI ${ }^{4}$, L. MOFFORD $^{4} \&$ P. TANG $^{5}$ \\ ${ }^{1}$ National Space Institute, Technical University of Denmark, Denmark. \\ ${ }^{2}$ Department of Geodesy and Geomatics Engineering, University of New Brunswick, Canada. \\ ${ }^{3}$ Faculty of Computer Science, University of New Brunswick, Canada. \\ ${ }^{4}$ New Brunswick Emergency Measures Organization, Canada. \\ ${ }^{5}$ New Brunswick Department of Environment, Canada
}

\begin{abstract}
Populations are usually unprepared for natural disasters (even in regions of high risk), and emergency planners are faced with the difficult task of evacuating these unprepared people quickly. Recent advances in Geographic Information Systems (GIS) technology allow for improved determination and mapping of risks for different natural and man-made disasters. Large amounts of data can be acquired, processed, analysed and displayed on digital maps, thus allowing the decision makers to assess the situation rapidly and take appropriate actions. Advanced hydrological tools for computation and modelling of natural hazards (such as floods) can be combined with GIS tools that have the capability of decision support and advanced visualization. This combination can be used to produce models that will represent the risks of natural and man-made disasters in the form of risk maps. Furthermore, these processes can be automated, which can allow for near real-time access to the risk maps. This can greatly help decision makers with emergency and mitigation measures, however the challenge is to design tools that meet the specific needs of emergency managers charged with the protection of a diverse and under-prepared populace. The research aimed to demonstrate the potential of GIS mapping tools with reference to two real case studies in Fredericton, New Brunswick, Canada. The first one relates to flood risk mapping needed for the evacuation of vulnerable populations, while in the second one, the mapping of a catastrophic flood scenario due to a dam break is presented.

The results of both case studies has helped to identify that the evacuation of socially vulnerable sections of the population require more resources and emergency planning than the evacuation of the rest of population. The socially vulnerable population needs to be registered before the disaster occurs and their special needs need to be documented. The response time needed to evacuate people, especially those who are socially vulnerable is very important in saving lives. There exist a number of important factors when planning for an evacuation, e.g. the number of people to be evacuated, time available for the evacuations, the distance to travel and also the available routes for evacuation. The provisions of medicaments, special food and any additional resources have to be planned and prepared in advance. Here, the approach to identify, map and assist the evacuation of socially vulnerable population during flooding in Fredericton while taking care of their special needs is presented. The main result of this research is a web-based GIS system that provides appropriate information to the relevant authorities and general public in a timely manner and easy to understand.
\end{abstract}

Keywords: early warning system, evacuation, flooding, risk maps, vulnerable population.

\section{INTRODUCTION}

Risk maps are becoming more and more important in emergency management, natural disasters or man provoked disasters as well as in environmental protection [1,2]. In this research, the emphasis is to investigate the applicability of web-based Geographic Information Systems (GIS) applications [2] for generation of risk maps. It will be shown how the flood risk maps can be generated in near real time, and the potential for mapping of the catastrophic flood events will be further explored. The two different cases will be presented; one dealing with natural floods and the evacuation of the vulnerable population and 
another one will present potential man-made disaster, the catastrophic flooding caused by the dam's burst.

The first task of this research is to create a web-based GIS application, which would help people living in flood plains, who may at one point be vulnerable due to their proximity to the river and the amplitude of the flooding. There are many factors that may lead to floods, and people living in flood plains are most likely to be affected. A flood plain is whereby a flat or gently sloping land adjacent to a stream, during high stream flow conditions, caused by excessive rainfall or snowmelt or a combination of the two, becomes inundated by water [3]. A large number of people in the Fredericton area reside along the Saint John River and its tributaries. In this research project the aim was to create a web-based GIS application $[1,2,4]$ that would provide timely flood information to emergency managers and general population, and the main functionalities of this application are to help identify people within certain distances within the floodplain, that may be affected by a particular flood. Web-based GIS [5] is a methodology of building distributed GIS applications on the Internet [6]. Web-GIS offers the possibility of querying on a website that can help to identify the properties and the people who might be affected by the floods and who may then be contacted to have ample evacuation time.

Natural disasters normally find people unprepared and emergency planners are faced with a big task of evacuating people. This paper also investigates how mapping of social vulnerable population can assist emergency planners in successful evacuation and allocation of resources. According to Hansjurgens [7], social vulnerability refers to the characteristics of a person or group and their situation that influence their capacity to anticipate, cope with, resist or recover from the impact of a hazard. He also argues that people/societies may be vulnerable to floods in terms of being less likely to be aware of flood risk, secondly, being less able to cope with it and respond to the threat, and thirdly, being less able to recover afterwards.

\subsection{Study area}

It has been identified that more than $58 \%$ of the incorporated municipalities in the region of New Brunswick (see Fig. 1), reside within the Saint John River System [8]. The reason being that the waterways, during early settlement years, served not only as a source of major transportation for the early settlers, it also served as a source of livelihood for them as well. As the New Brunswick communities grew, so did the occupation of flood plains to the point where substantial damages, human sufferings and indeed, loss of lives occurred during major floods [1].

Furthermore, a publication by Jeanne Andrews [9] on flooding, highlighted the fact that flooding in Canada was a common phenomenon, resulting from an increase in stream flow beyond the point where the normal stream channel could contain the water. However, in most cases, flood-prone areas are often very attractive to the developer.

\section{PROTOTYPE APPLICATION DESIGN AND IMPLEMENTATION}

Since ancient times, humans have developed means to monitor flood levels and to some extent, predict the rate of flood rise. People in medieval times marked animals and push them down the river to see how deep the river was. Today, more innovative technologies have been developed to study floodings $[10,11]$. These include satellite remote sensing, aerial photogrammetry and LiDAR. Such technologies are combined with computer terrain modelling tools to create scenarios for analysis, as in the case of GIS.

With the advent of robust computer tools and high accuracy Digital Terrain Model (DTM), automated floodplain delineation is achievable [12]. Recently, several management systems 


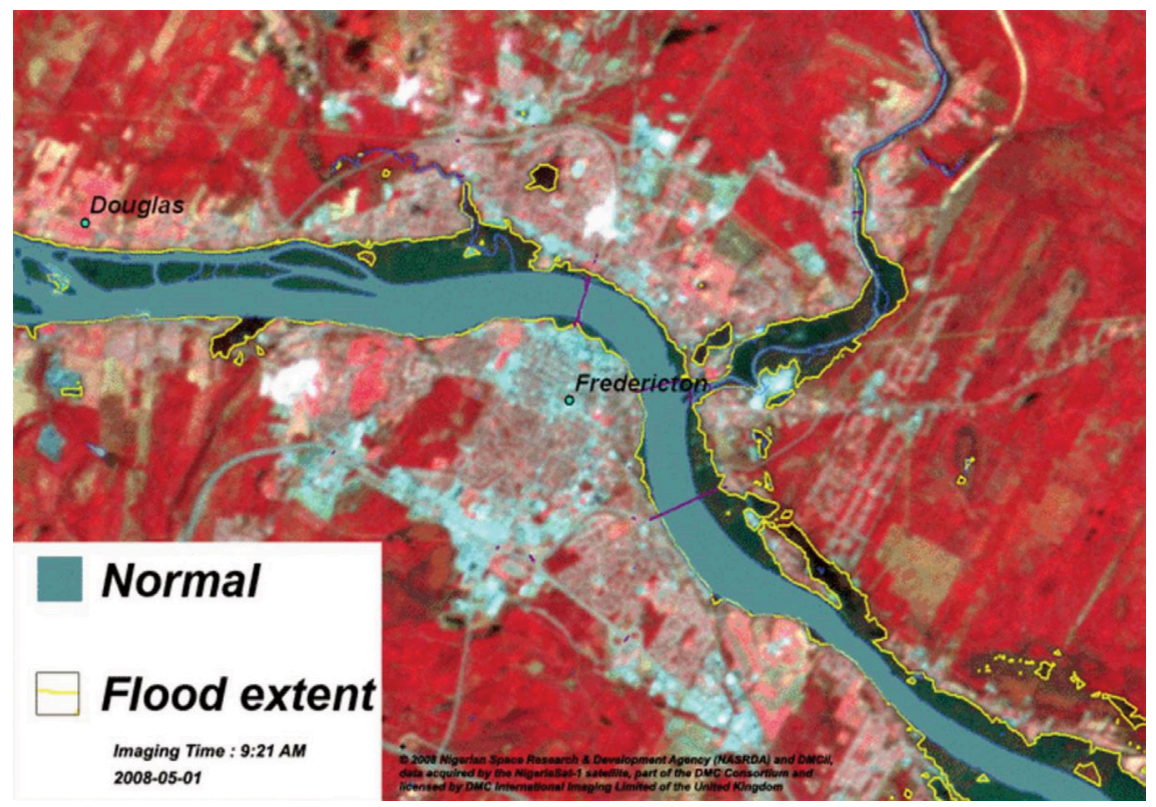

Figure 1: Satellite image of the study area taken during the flood in 2008.

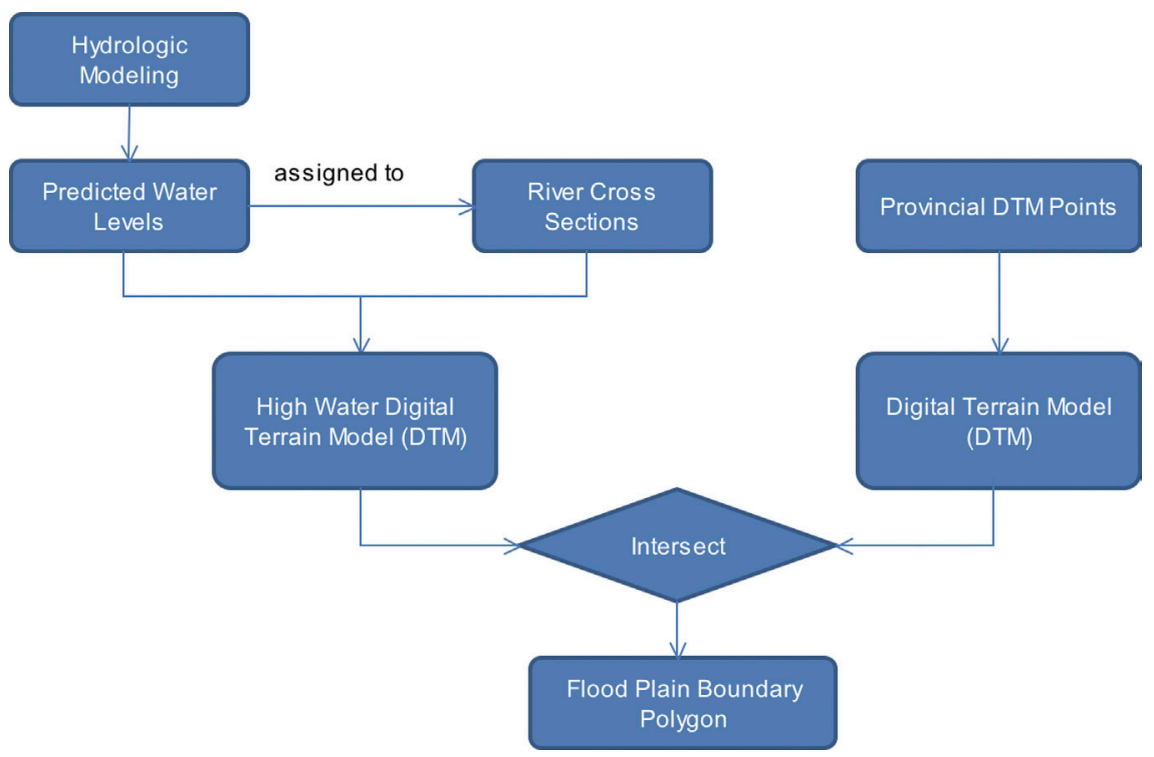

Figure 2: The workflow of the calculation of predicted floodplain.

for floodplain delineation have been developed and applied in the flood event areas. These include floodplain delineation using Watershed Modeling System [13], SMS [14], MIKE11 [15] and HEC-GeoRAS [16]. All of the above systems are required to combine the output of the hydrological model with the ArcGIS system. As shown in Fig. 2, the most significant 




Figure 3: Floodplain delineation process - computation of water surface TIN (the thick edges are constrained Delaunay edges corresponding to cross sections, while the thin edges are Delaunay edges that do not correspond to cross sections).

inputs for automated floodplain delineation (automated floodplain delineation is an excellent tool for producing floodplain extent maps [12].) are the DTM and the water levels on the sections shown on Figure 3. The process considers the DTM and water levels at different locations to determine the direction and extent of flow over a floodplain for a given hydrologic event.

Previously, the New Brunswick Emergency Measures Organization (EMO) in collaboration with the University of New Brunswick, Canada, developed a flood model (available from http://www.gnb.ca/public/Riverwatch/index-e.asp) for the area of lower St. John River, New Brunswick, Canada [17,18].

The next objective was to create a web-based GIS system, which could provide appropriate information to the relevant authorities in a timely manner and easy to understand. Relevant authorities in this case may include flood managers, flood warning practitioners, professional partners and emergency services to those affected [19]. Furthermore, the flood warnings available online and readily accessible to a broad audience can increase the level and quality of services provided [1].

The easy-to-use interface (see Fig. 4) should also allow non-GIS experts to be in a position to interactively view and explore, as well as query the database, to select different data variables and to view maps at several levels of detail. The ArcIMS was used to develop the web-based GIS system [20]. When creating this website, it was taken into consideration that the provision of a map-based information system in an easily accessible manner presents 


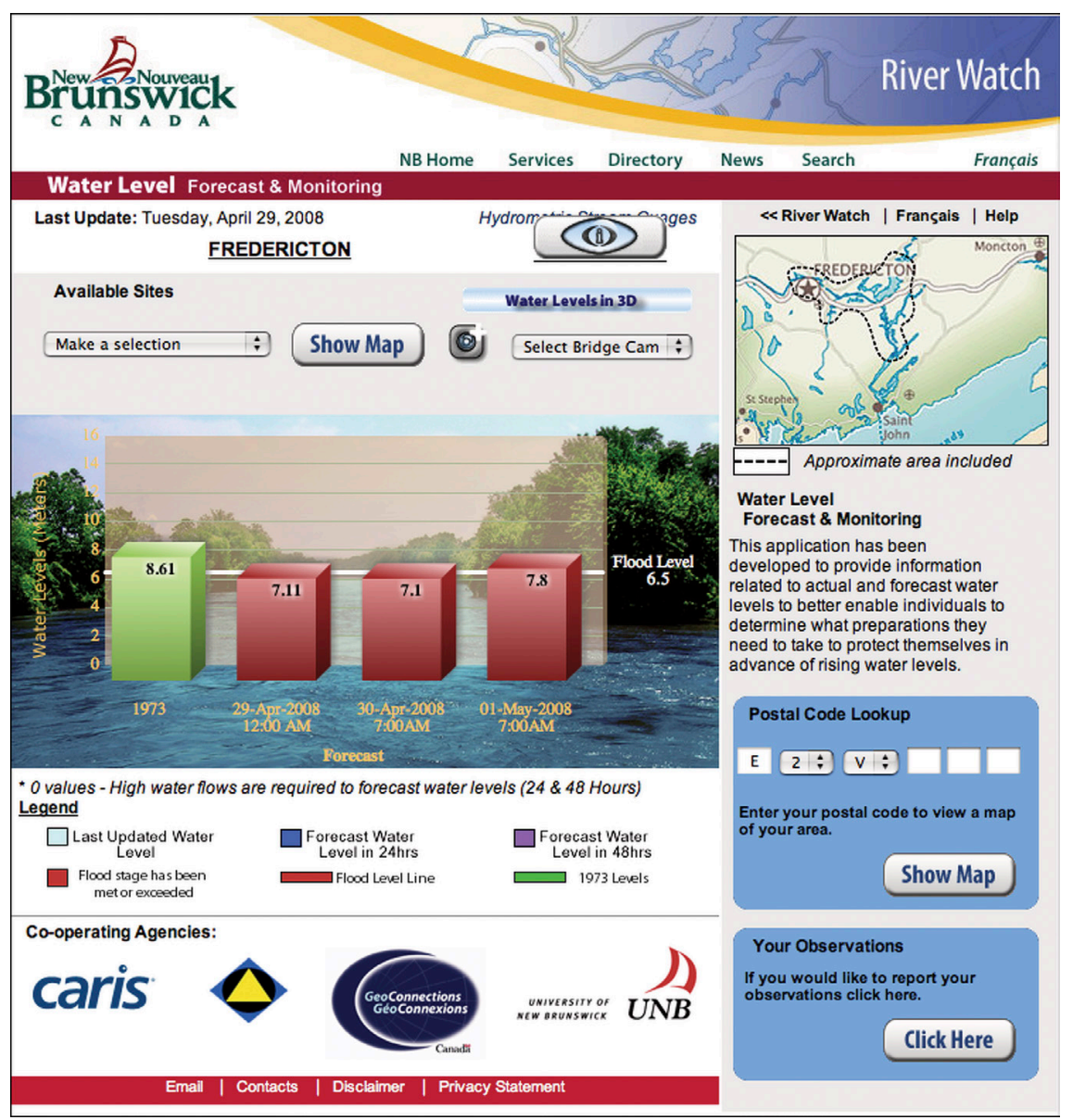

Figure 4: New Brunswick River Watch web site (prototype) for flood warning in the lower St. John River watershed.

many challenges and as such, most search results displayed on the map would also be accompanied by textual sections below the map.

Flooding is common in Fredericton and the 1973 flood (shown on the map in Fig. 2) was considered to be the worst according to the officials of the City of Fredericton [21] and recently in 2008 CBC News [22] reported that about 40 streets were expected to be closed with water rising to levels above the 1973 flood. The same report mentions that 1300 homes would be affected in the process.

Usually, people who live in the area that is being flooded are required to evacuate. The evacuation crews often need to take care of the vulnerable population, and in order to assist the population in real-life situations, the mapping of this vulnerability should be web-based [23]. This will allow emergency people to be able to access the information from the evacuation areas without having to rely on the GIS data sitting back at their offices. Watson [24] argues that it is important to get maps instantly with every team member. He also refers to the new technology that bridges the gap between a geospatial expert and a non-expert. 




Figure 5: Output of a manually entered query.

Usually, evacuation planning takes into account the following information:

- Characteristics of the hazard, e.g. speed, duration, impact.

- Number of people to be evacuated.

- Time available.

- Distance to travel to ensure safety.

- Evacuation routes.

The evacuation process during flooding also requires information on accessible roads and in this research, the vulnerability maps also show the location of temporary shelters to accommodate the evacuated population. It will also indicate the location of hospitals allowing to the emergency planners to find the nearest hospital for the evacuation area.

The main objectives include:

- To assist flood warning practitioners and the general public in near real time to query the website for flood evacuation routes, and to have an idea of the water levels on flooded roads (see Figs. 5 and 6).

- Design floods have also been utilised, for the system to assure the capability of identifying the properties that can be affected by a particular design flood. The design floods used in this research are of 1 in 20-year flood, that is a flood having a return period of 20 years on average or having a $0.05 \%$ chance of occurring in a given year. Other design floods are 1 in 100-year and 1 in 200-year floods. These are intersected with the land use classification layer that includes industrial areas, offices, parks, shopping areas and residential blocks of people residing within the flood plain (see Figs 1, 6 and 7). This can be very helpful to flood practitioners to have an idea of the properties likely to be affected by such a flood 




Figure 6: Properties affected by a particular flood water depth.

Table 1: Identified property data.

\begin{tabular}{rlllrlrrrrr}
\hline 240 & 2487100.8 & 7441993.85 & 01413871 & 100 & 1973 & 3 & 0 & 2 & [polygon] & 17485 \\
241 & 2487144.05 & 7441996.15 & 01413384 & 100 & 1973 & 3 & 0 & 2 & [polygon] & 17564 \\
242 & 2487176.95 & 7442030.8 & 01415140 & 0 & 1973 & 3 & 0 & 2 & [polygon] & 17618 \\
243 & 2486932.05 & 7441933.5 & 75237180 & 100 & 1973 & 3 & 20 & 2 & [polygon] & 17787 \\
\hline
\end{tabular}

(see Figs 6 and 7). Furthermore, city planners may also utilize the data when planning for future developments on flood prone areas to have a idea on the extent of the flood coverage of a possible maximal flood (shown in Figs 1 and 6).

Areas highlighted in yellow (see Fig. 6) show the properties likely to be affected by a water level of 3, which is up to $0.5 \mathrm{~m}$. In total, 243 properties would be affected by this water level rise (shown in Fig. 6 and in Table 1):

\section{MAPPING THE FLOOD EXTENT DURING THE FLOOD EVENTS}

Nation-wide surveys $[3,8,9,25]$ have been made in the past and they clearly show that New Brunswick area is highly vulnerable to floods.

Furthermore, city planners may also utilize the data when planning for future developments on flood prone areas to have an idea on the extent flood coverage of a possible maximal flood (shown in Figs 1, 6 and 7).

The idea is to use design floods, defined by Jeanne Andrews' publication on floods [9] to be extreme flood events selected and used for the design of structural measures such as dykes, 


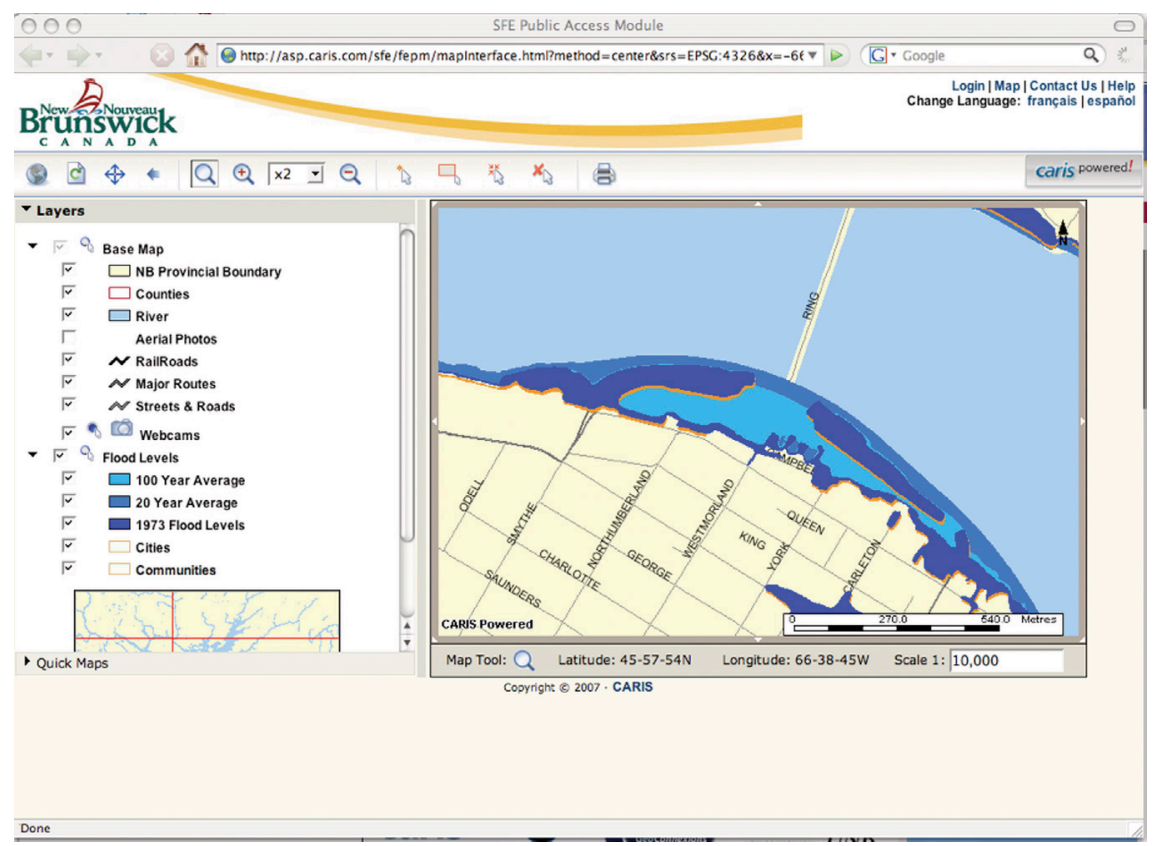

Figure 7: Map displaying statistically significant floods.

spillways and floodways, as well as used in the delineation on topographic maps of flood hazard areas adjacent to rivers, lakes and the sea.

Using the web-GIS in this project provided the possibility of query on the website that can help to identify the properties and the people who might be affected by the floods, who may then been contacted to have ample evacuation time. In this research near real-time prognostic of the flood maps were used [1].

The dynamic mapping of flood risk on daily basis was implemented by River Watch [25, $26]$ by using the daily available data about the river water levels obtained from the water gauges. Furthermore, the data about the streams and rivers in the Fredericton area and the road networks data are used to calculate the available evacuation routes $[23,26]$.

The new risk maps with the updated extent of the floodplain are calculated on a daily basis using the hydrological modelling [1] interfaced with GIS and displayed in dynamic and interactive manner (see Fig. 8).

\section{MAPPING OF SOCIAL VULNERABILITY}

Now, the mapping of the social vulnerability of each parcel that was affected by the 1973 flood will be presented. The 1973 flood extent was chosen because it was one of the worst floods (according to Fredericton officials) in recent times in Fredericton and the data were readily available.

The mapping of social vulnerability was first introduced in [27]. There exists some calculation for social vulnerability, but they have all looked at blocks of population (usually determined by the zip or postal codes) and not necessarily at each parcel $[19,20]$. The block group is the analytical unit that provides the smallest census unit with detailed demographic and socioeconomic data [20]. Chakraborty et al. [20] introduced a social vulnerability for Evacuation Assistance Index (SVEAI), which combines vulnerability factors. 


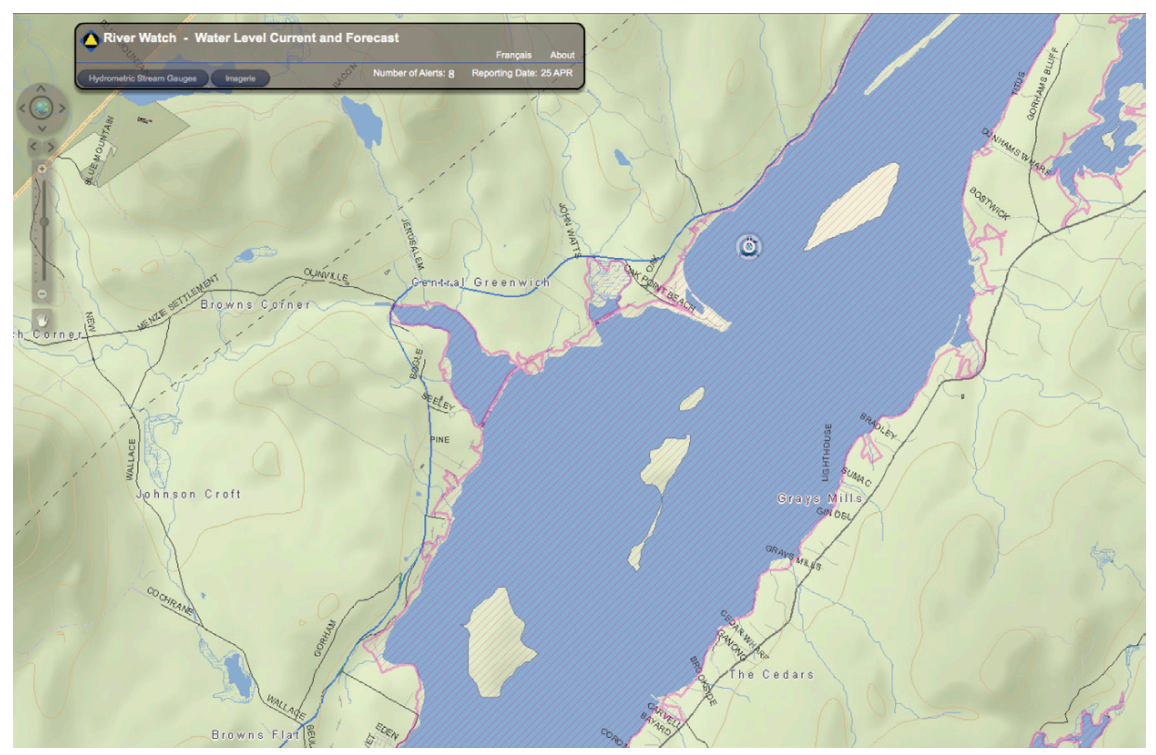

Figure 8: Flood warning application - River watch [25].

This formula was used for the Hillsborough County, FL, and it works as follows:

1. For each variable $i$, determine the ratio of the variable in the block group to the summation of that variable in the county $\left(R_{i}\right)$.

2. Compute a standardized Social Vulnerability for EvAcuation Index $\left(\mathrm{SVEAI}_{i}\right)$ for variable $i$ using the maximum ratio value $R_{\max }$ observed in the county

$$
\text { SVEAI } i=\frac{R i}{R \max }
$$

3. To combine multiple variables in the assessment of social vulnerability, calculate the arithmetic mean of the vulnerability indices by dividing the sum of index values of all variables by the number of variables $(n)$ considered

$$
\mathrm{SVEAI}=\sum \frac{\mathrm{SVEAI} i}{\mathrm{n}}
$$

This formula was adopted from Cutter et al. [27] who introduced a Social Vulnerability Index (SOVI). Cutter's formula is used to calculate social vulnerability for counties.

The above-mentioned approaches work with groups of people, but this paper attempts to demonstrate that mapping information at parcel level can be more useful to emergency planners during evacuation.

Cutter et al. [27] identified the following as indicators of Social Vulnerability:

- Age, gender, race, and socioeconomic status.

- Characteristics depicting special needs populations or those who lack the normal social safety nets necessary in disaster recovery.

- The quality of human settlements (housing type and construction, infrastructure and lifelines) and the built environment. 
The approach of this paper will not be based on a formula or any weighting system. The approach presented by Cutter et al. [27] is not applicable for real evacuation of population as the emergency managers need to work with parcel data and not with the block group data. The indicators will be mapped as they are or grouped according to level of assistance required.

Based on the past experience of emergency managers in New Brunswick, the following classification is used in this application:

- The first class (see Table 2) will comprise households that have people requiring medical assistance or population aged over 85 years. Then, another group of people above the age of 5 years and with disabilities is defined.

- The third class will be people with kids under the age of 5 years and the fourth class will be families without cars or living in mobile homes.

- The last class will be people who can evacuate with little or no outside help.

Table 2 summarizes the vulnerability classes in this GIS application.

Table 2: Vulnerability classes.

\begin{tabular}{ll}
\hline Vulnerability class & Description \\
\hline A & $\begin{array}{l}\text { Population requiring medical assistance or Population above } \\
\text { the age of } 85 \text { years }\end{array}$ \\
B & Population with disabilities \\
C & Kids under the age of 5 \\
D & Families in mobile home or families without cars \\
E & Population capable of self-evacuation \\
\hline
\end{tabular}

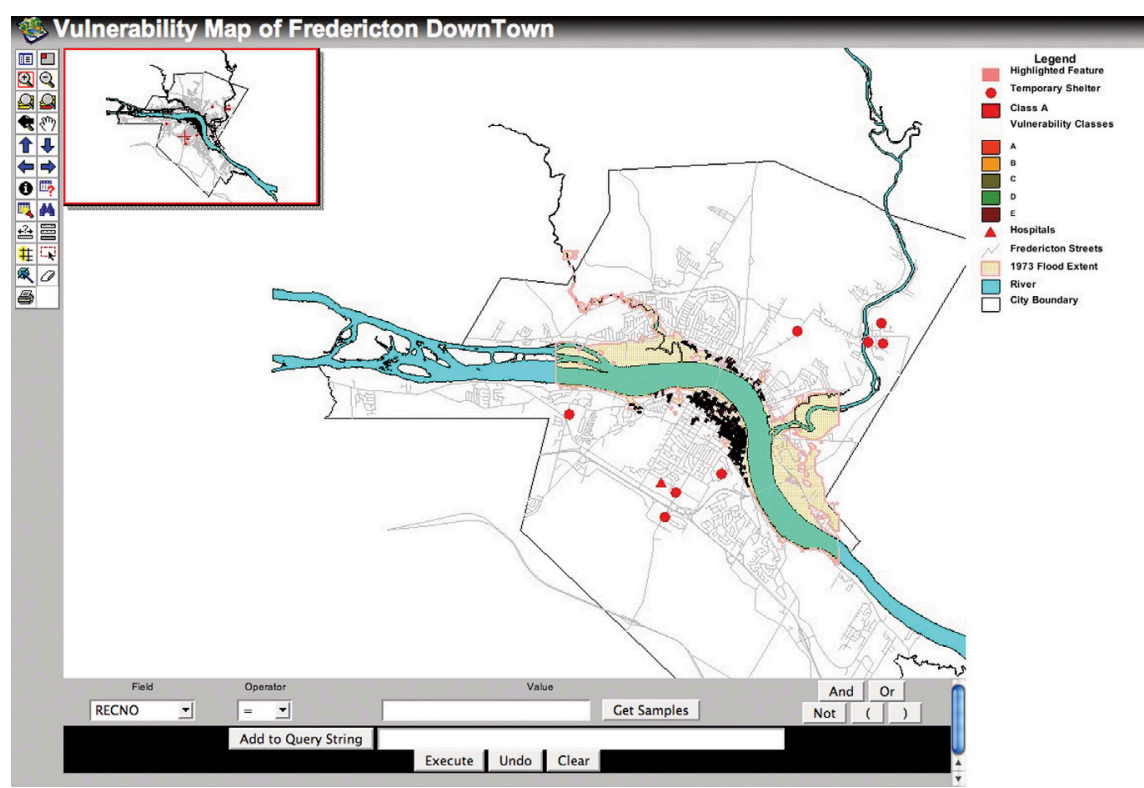

Figure 9: Web-GIS application for mapping the socially vulnerable population during flooding. 
Given this kind of information (see Fig. 9), emergency planners can know which households to assist first and also what resources to carry during the evacuation process. It is also acknowledged that a household can comprise one or more of the above classes, but in this case a household is given a class of the person/persons requiring the most assistance.

\section{THE WEB-GIS APPLICATION FOR EVACUATION OF SOCIALLY VULNERABLE POPULATION}

For web-based implementation of the early warning system for evacuation of socially vulnerable population, it was decided to use ESRI ArcIMS software. ArcIMS offers two main templates, one based on HTML and another that runs through Java applets. The HTML template and the ArcGIS server have an advantage in that they do not require installation of Java on a client's computer to run. On the other hand a Java template offers an editing capability in the form of map notes that can be very useful for emergency planners.

Given the MapNotes functionality, users can create notes of their application and share with other users of the same Internet GIS application.

To give an example, each team can easily create a new point symbol for each household they have evacuated. This information can then be shared with other teams, so that teams that have finished their work can know which households still require assistance. At the same time, the progress can be centrally monitored to ensure that people are evacuated timely or if there is extra help required.

The ArcIMS HTML view was adopted for this paper. The application has eight data sets shown in Fig. 10:

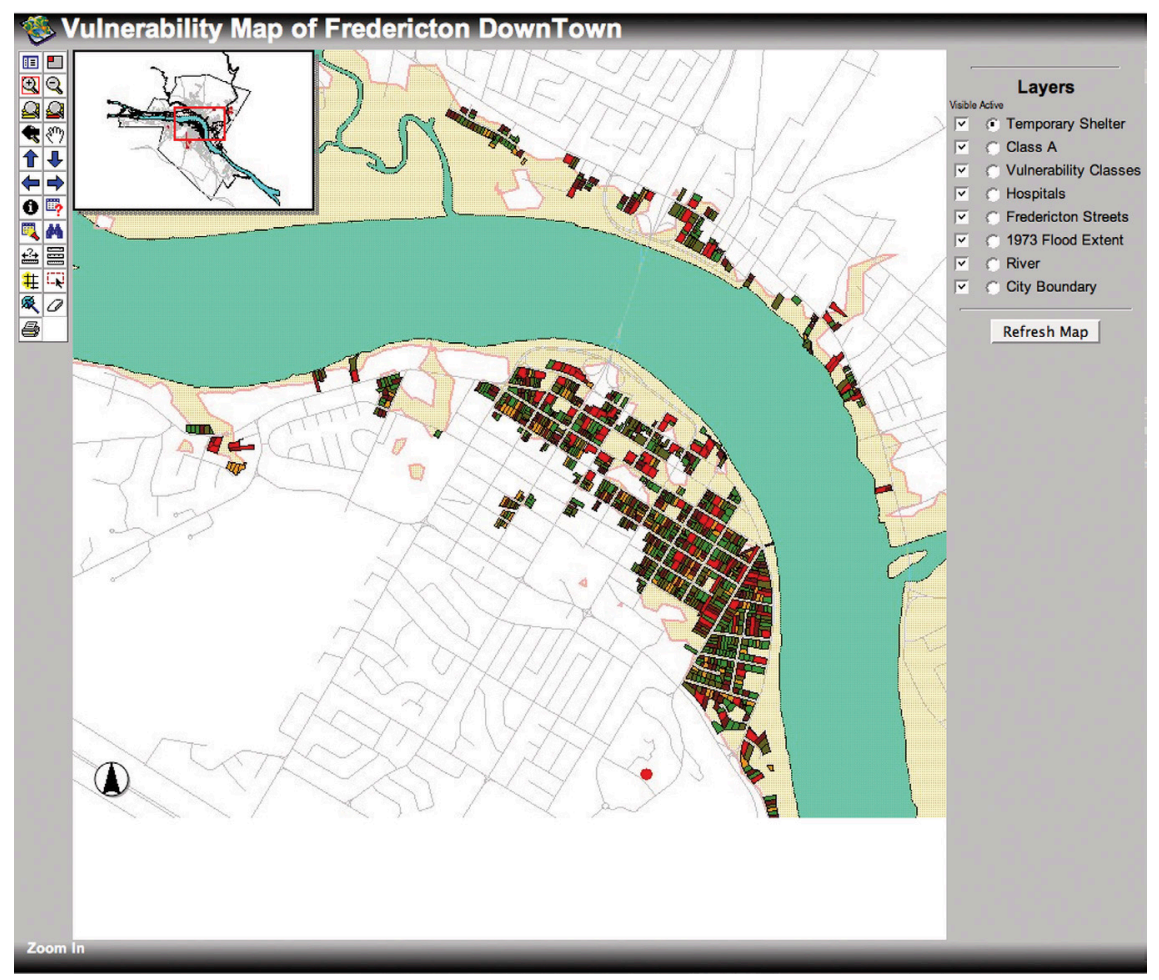

Figure 10: Data layers on the map available for the queries. 
- Vulnerability classes (where simulated data were used due to the Canadian privacy laws).

- Class A (from vulnerability classes).

- Temporary shelter.

- Hospitals.

- 1973 Flood extent.

- St. John river.

- Fredericton streets.

- City boundary.

The database for Class A was created separately to show medical conditions of the people requiring assistance during evacuation. Given these extra details, the emergency planners can therefore select the appropriate shelters for the evacuated population using information from the shelters (see Table 3 and Fig. 10). The data sets and available queries are presented in Table 3 [23].

In this application, the sample values for each query are provided for the guidance of non-experienced users (see Figs 11 and 12).

ArcIMS allows queries of one data set at a time, i.e. a user cannot query two or more data sets at the same time. For example, a user can only query Vulnerability classes and it cannot combine the query with one from Temporary shelters (shown in Fig. 12).

\section{MAPPING THE POTENTIAL EXTENT OF A CATASTROPHIC FLOOD EVENT CAUSED BY A DAM BREAK}

The Mactaquac Dam (constructed between 1965 and 1968 [28-30]) is an embankment dam used to generate hydroelectricity and it is located near City of Fredericton, in the Canadian province of New Brunswick. The construction of the Mactaquac dam was promoted within by the New Brunswick Government and the New Brunswick Electric Power Commission (NBEPC), within 'power for industry' campaign as a necessary and progressive step towards the industrialization $[29,30]$.

Its electrical power is $653 \mathrm{~mW}$, what represents approximately $20 \%$ of New Brunswick's power demand [31]. The dam construction involved the relocation of existing villages and inhabitants and creation of the artificial lake [30].

The dam is constructed between two concrete spill-ways to form an arch across a narrow section of the river between the communities of Kingsclear on the west bank, and Keswick Ridge on the east bank. The dam is located approximately at $15 \mathrm{~km}$ upstream from the city of Fredericton [30,31].

The Mactaquac dam reservoir is approximately $40 \mathrm{~m}$ higher than the downstream river level. The area of the artificial lake covers $87 \mathrm{~km}^{2}$ and extends $96 \mathrm{~km}$ upstream. The Mactaquac reservoir has no additional water holding capacity or retention area in the event of

Table 3: Summary of the queries available within the application.

\begin{tabular}{ll}
\hline Data set & Queries available \\
Vulnerability classes & Number of residents, vulnerability class \\
Class A & Number of residents, medical condition \\
Temporary shelter & Shelter name, capacity, available support equipment \\
Fredericton streets & Street name \\
\hline
\end{tabular}






Figure 11: Query example for Class A.

unusually high water flows that occur during the spring freshet [31,32]. This creates additional risks and can cause dam breach during the extreme flood events.

The locally quarried gravel that was used to produce in concrete portions of the Mactaquac dam (namely the spill-ways) is believed to be responsible for the alkali-aggregate reaction expansion of the concrete [33]. The Mactaquac dam is being monitored and surveyed regularly and extra maintenance work is being performed, but the research results show that the spill-way is expected to have a reduced life expectancy [28,31].

The recent hydrological events like flush floods are enhanced by climate change affecting the Eastern provinces of Canada. Such events can intensify the danger of dam burst due to the influx of the large amount of rain water. The Mactaquac dam burst is a hypothetical event that could have devastating consequences for the population of New Brunswick.

Previous work [1] on the flood mapping and prototype development relied on the commercial web-GIS packages. In this research work, the querying and data processing were slow, and the application did not have the capability and functionality for displaying 3D buildings available from City of Fredericton [34,35]. The Google Earth was used instead of commercial GIS packages for visualization of the catastrophic flooding scenario. The easy to use 


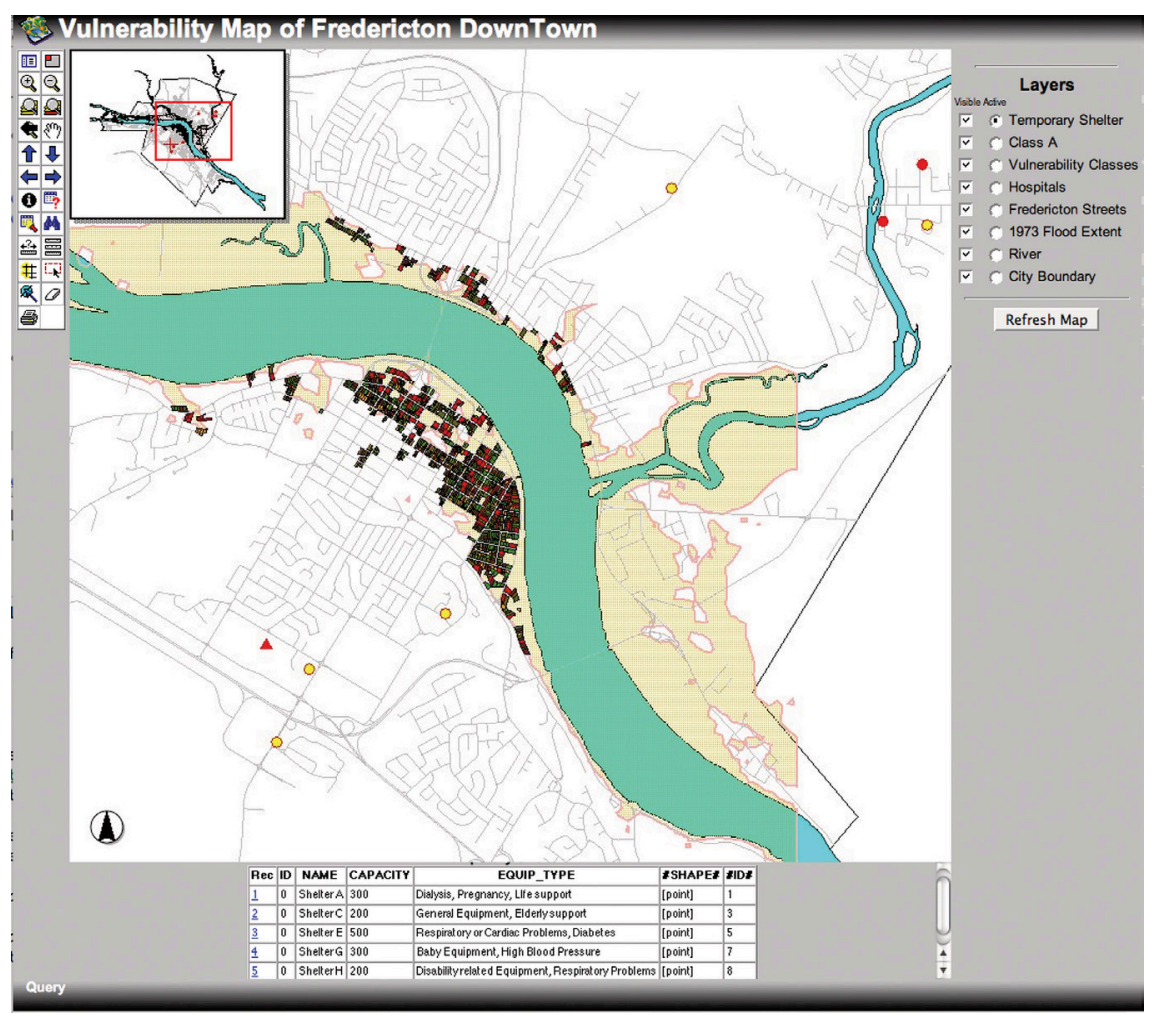

Figure 12: Query for the facilities available in temporary shelters.

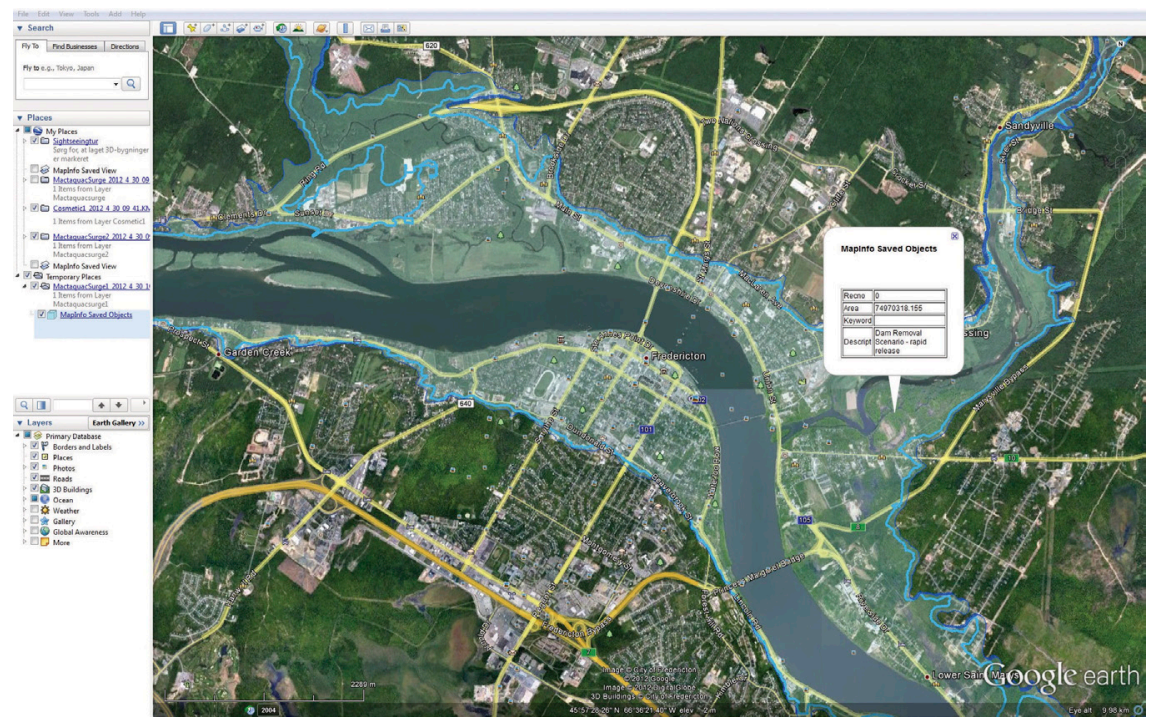

Figure 13. Two dam break scenarios integrated and displayed within Google Earth. 
interface (see Fig. 13) provided by Google Earth should also allow non-GIS experts to be in a position to interactively view and explore, as well as query the data base, to select different data variables and to view maps at several levels of detail. The hydrological modelling of the dam break was done as a part of the flood monitoring and prediction project by River Watch $[25,35,36]$. As a part of flood modelling, the possible catastrophic flood due to the Mactaquac dam burst have been mapped as well.

The two scenarios of Mactaquac dam breach were considered; one with the reservoir not full (see Fig. 13), and under the normal operation of the dam called 'Sunny Day' (marked with the dark blue line), while the other deals with the dam removal scenario [35] and it is also shown in Fig. 13 (light blue line).

The earliest projections put the dam's end of life at 2028, instead of the original 100-year lifespan of 2068, because the concrete used to build the powerhouse and spillways began expanding and causing cracks [20].

The Mactaquac dam burst scenario has also been implemented using ArcIMS, thus allowing for the query (see Fig. 14) and spatial analysis [1]. The users of this application can visualize the extent of the flood in the city as well as the houses likely to be affected by such a scenario (see Fig. 14). In Fig. 15, the effect of the catastrophic flooding on downtown Fredericton can be visualized as well as 3D buildings developed by the City of Fredericton. The models of 3D buildings developed by the City of Fredericton can be observed as well [34]. On Figure 15 the 'Zoom-In' function allows one to identify the area of downtown Fredericton that could be affected by the catastrophic flood under the Mactaquac dam burst scenario [37]. Furthermore, the shelters and the hospitals available to the population are identified and mapped [23] as shown in Fig. 9.

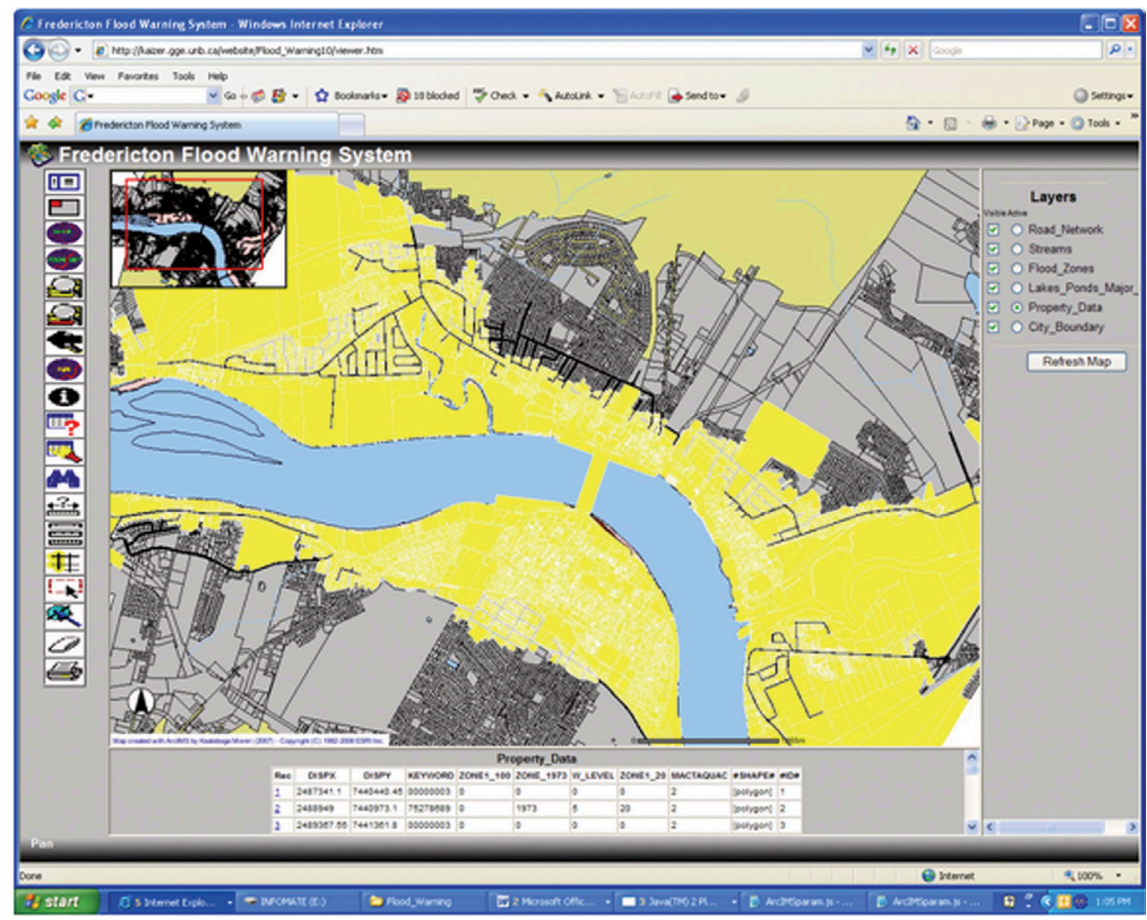

Figure 14: Web-GIS application for Mactaquac dam burst scenario. 


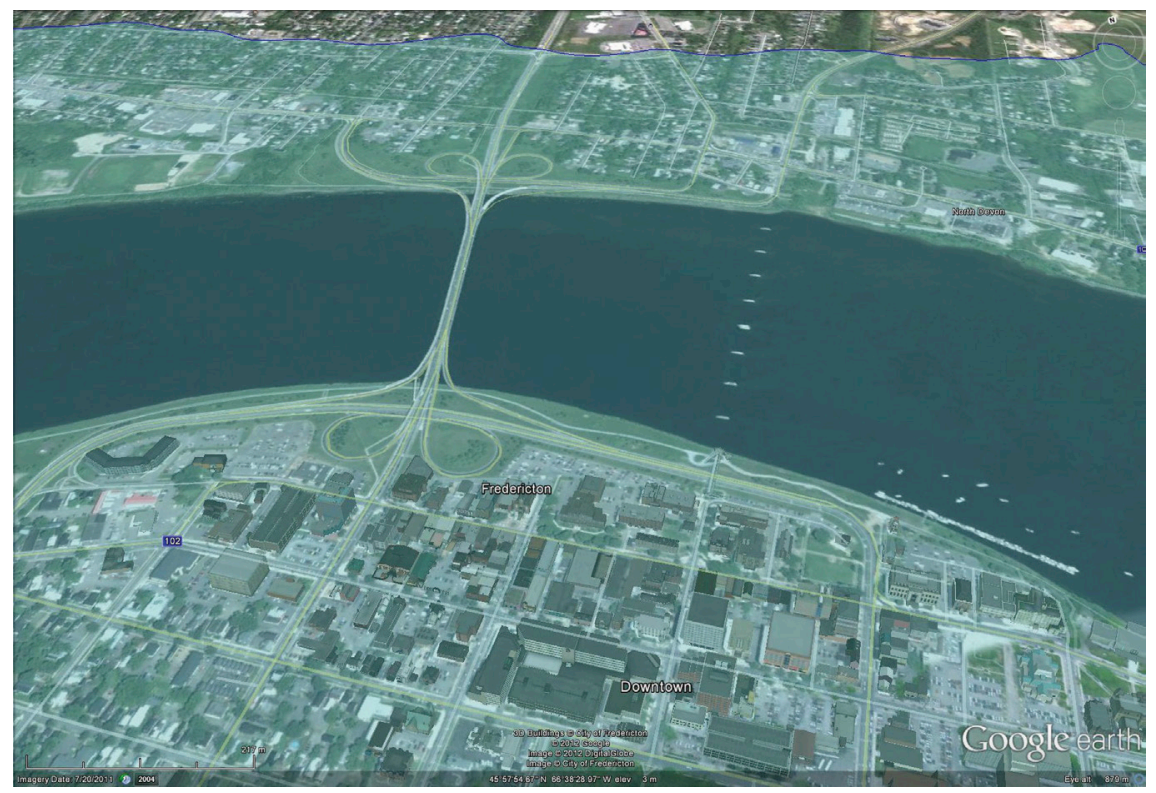

Figure 15: The view of the 3D buildings affected by catastrophic flood in downtown Fredericton.

\section{CONCLUSIONS}

In this research, it has been shown that with the recent advances of GIS technology, it is now possible to map and determine the risks (together with their magnitude) of different natural hazards and man-made catastrophes. Very large amounts of collected spatial and non-spatial data can be processed, quantified and displayed on digital maps, even in near real-time applications, thus allowing decision makers to assess the situation rapidly and to take appropriate actions.

The use of advanced tools for computation and modelling of natural hazards such as floods can be combined with a GIS that has the capability of decision support and advanced visualization to produce the models, that represents the risks of natural hazards and man-made disasters in the form of dynamic risk maps, where the risks are categorized and quantified. In this paper, it is shown that the simple mapping application can be done using Google Earth, and provides excellent visualization of the effects of the catastrophic flood caused by the Mactaquac dam breach.

The results of this research provide a prototype of the near real-time, web-based application for Fredericton's flood warning system, where accurate and timely warnings can be achieved, and thus maximizing the response time for flood plain residents and emergency managers and to provide a powerful planning tool for flood prone areas. Furthermore, proper evacuation routes can be planned well on time, when water depths on several streets likely to be affected by the floods are known. The idea was to bring the results that would show the inundation at a particular level, represented by a colour code, for example, having to represent the selections of a particular water level with a particular colour for clear distinction. 
This could be also done in near real-time and can significantly improve the flood evacuation requirements for emergency planners.

The developed web-GIS application can assist flood warning practitioners as well as individual people to query the website, for flood evacuation routes; as such the website would allow them to identify evacuation routes as well as to assess the water levels on flooded roads. The flood warnings application is available online and readily accessible to a broad audience to increase the level and quality of services provided.

Using the results of hydrological modelling, the system has the capability of identifying the properties that may be affected by an upcoming flood. This can be very helpful for flood practitioners to have an idea of the properties that could be affected by flooding.

Furthermore, the mapping of socially vulnerable population affected by the flood is presented. Population evacuation in times of disasters is a very important factor and mapping of socially vulnerable population in those areas could help emergency planners in their efforts to evacuate people. This mapping combined with physical hazards and other warning measures have important roles in saving lives and also helping people recover after disasters.

In this research project, it was shown that all these data processing and mapping can be automated, enabling near real-time access to the risk maps via map servers. This can greatly help general public as well as to decision makers with the emergency measures like evacuation and mitigation in most of the cases.

\section{ACKNOWLEDGEMENTS}

This project was financially supported, in part, by the NB Emergency Measures Organization and by the Canadian Department of Natural Resources Geoconnections programas well as by University of New Brunswick and New Brunswick Innovation Foundation (NBIF). The IT Division of the City of Fredericton and Geological Survey of New Brunswick provided data sets available for this project. The New Brunswick Department of Environment has provided data and expertise related to hydrological modelling, and the NB Emergency Measures Organization helped with their expertise and additional funding for this project.

\section{REFERENCES}

[1] Mioc, D., Moreiri, K.K., Nkhwanana, J.N., Anton, F., Nikerson, B., McGillivray, E., Morton, A. \& Tang, P., On-line early warning system for evacuation of socially vulnerable population during flooding. Flood Recovery, Innovation and Response III, Ed. D. Proverbs, S. Mambretti, C.A. Brebbia \& D. de Wrachien, WIT Transactions on Ecology and the Environment, Vol. 159 (ISBN: 978-1-84564-588-5), Ashurst, Southampton, UK, pp. 67-78, 2012. doi: http://dx.doi.org/10.2495/friar120061

[2] Konecny, M., Early warning and crisis management cartographic and geographic information research agenda. Proc. of the 4th International Conference on Cartography and GIS, Vol. 2., June 18-22, Albena, Bulgaria, pp. 7-16, 2012.

[3] Spear MacDonald and Associates Limited, Cumming - Cockburn and Associates, Canada, New Brunswick Program for a Hydrotechnical Study of the Walker Brook Flood Plain, Summary Report, 1983, revised in 1985.

[4] Mioc, D., Anton, F., Nickerson, B., Santos, M., Adda, P., Tienaah, T., Ahmad, A., Mezouaghi, M., MacGillivray, E., Morton, A. \& Tang, P., Flood progression modelling 
and impact analysis, Efficient Decision Support Systems - Practice and Challenges in Multidisciplinary Domains, C. Jao (ed.), ISBN: 978-953-307-441-2, Vukovar, Croatia, pp. 227-246, InTech, 2011. doi: http://dx.doi.org/10.5772/18398

[5] Zipf, A. \& Leiner, R., Mobile internet GIS based flood warning and information systems, 2nd Symposium on Location Based Services and TeleCartography, Vienna, Austria, 2004.

[6] Shea, G.Y.K., A Web-Based Approach to the Integration of Diverse Data Structures for GIS, School of Surveying and Spatial Information Systems, Sydney, NSW, 43 pp, 2001.

[7] Hansjurgens, B., Megacities, risk and social vulnerability, Helmholtz Association, Retrieved November 13, 2008, available at http://www.ehs.unu.edu/file.php?id=334, 2007.

[8] Department of the Environment, Water Resources Branch, Fredericton, Planning Region Water Resources Review, Report I - 8001, Environment Canada, Ottawa, Ontario, 1980.

[9] Andrews, J. (ed.), Flooding, Canada Water Book, Canada Communication Group, 1993.

[10] Jones, J.L., Mapping a Flood... Before It Happens. U.S. Geological Survey Fact Sheet 2004-3060, available at http://pubs.usgs.gov/fs/2004/3060/pdf/fs20043060.pdf, (accessed 5 June 2009).

[11] Marks, K. \& Bates, P., Integration of high-resolution topographic data with floodplain flow models. Hydrological Processes, 14(11-12), pp. 2109-2122, 2000. doi: http:// dx.doi.org/10.1002/1099-1085(20000815/30)14:11/12<2109::aid-hyp58>3.3.co;2-t

[12] Noman, N.S.; Nelson, E.J. \& Zundel, A.K., Improved process for floodplain delineation from digital terrain models. Journal of Water Resources Planning and Management, 129(5), pp. 427-436, 2003. doi: http://dx.doi.org/10.1061/(asce)07339496(2003)129:5(427)

[13] Environmental Modeling Research Laboratory (EMRL), Watershed Modeling System (WMS) Reference Manual and Tutorial, Environmental Modeling Research Laboratory (EMRL), Aquaveo, Provo, Utah, United States, 1998.

[14] Aquaveo, SMS Flood \& Storm Surge Modeling Solutions, available at: http://www. aquaveo.com/products, Online (accessed 2013).

[15] Danish Hydraulic Institute (DHI), MIKE11 GIS Reference and User Manual, DOH, 2004.

[16] Ackerman, C.T., HEC-GeoRAS; GIS Tools for support of HEC-RAS Using ArcGIS, Danish Hydraulic Institute: Hørsholm, Danmark. p. 204, 2005.

[17] Mioc, D., Moreiri, K.K., Nkhwanana, J.N., Nikerson, B., McGillivray, E., Morton, A. \& Tang, P., On-line early warning system for evacuation of socially vulnerable population during flooding, Flood Recovery, Innovation and Response III (ISBN: 978-1-84564588-5), WIT Press, Vol. 159, Ashurst, Southampton, UK, p. 284 2012. doi: http:// dx.doi.org/10.2495/friar120061

[18] Mioc, D., Nickerson, B., Anton, F, Fraser, D., McGillivray, E., Morton, A., Tang, P., Arp J. P. \& Liang G., Web-GIS application for flood prediction and monitoring, International Conference on Flood Recovery Innovation and Response, London, July 2008, 6 pp, available at library.witpress.com, 2008. doi: http://dx.doi.org/10.2495/friar080151

[19] Butts, M.B. \& Khatibi, R., Workpackage 7: Operational End-user Requirements General Functionality deliverable 7.1-Part 1, (FLOODRELIEF project), available at http://projects.dhi.dk/floodrelief 2003 (accessed 2003). 
[20] Moreri, K., Mioc, D., Anton, F., Nickerson, B., McGillivray, E., Morton, A., Fraser, D. \& Tang, P., Early warning and mapping for flood disasters, Joint ISCRAM-CHINA and Gi4DM Conference, Harbin, 6 pp, 2008.

[21] City of Fredericton, Internal documentation, available at http://www.fredericton.ca/en/ publicsafety/2008April1FloodWatch.asp (retrieved 2 December 2008).

[22] Canadian Broadcasting Corporation, $C B C$ News, available at http://www.cbc.ca/canada/ new-brunswick/story/2008/04/30/nb-flood.html, 2008 (retrieved 2 December 2008).

[23] Nkhwanana Nyaladzani, J. \& Mioc, D., Early warning system for evacuation of socially vulnerable population during flooding. Joint Symposium Cartography and Geoinformatics in Early Warning and Crises Management, Towards Better Solutions, Prague, 6 pp, January 19-22, 2009.

[24] Watson, C., Using GIS Data for Emergency Preparedness and Response, available at www.geoplace.com, Online (retrieved November 2008).

[25] River watch, available at http://geonb.snb.ca/riverwatch, Online (retrieved 2013).

[26] New Brunswick Department of Environment, River watch, Traffic Advisories/Flooding, available at http://www1.gnb.ca/cnb/transportation/flooding-e, Online (retrieved 2013).

[27] Cutter, S.L., Boruff, B.J. \& Shirley, W.N., Social vulnerability to environmental hazards. Social Science Quarterly, 84(2), pp. 242-261, 2003. doi: http://dx.doi. org/10.1111/1540-6237.8402002

[28] Report says Mactaquac Power Station in trouble, Posted on December 11, 2000, available at http://www.cbc.ca/news/canada/report-says-mactaquac-power-station-introuble-1.237718, (retrieved 1 October 2010).

[29] Construction of the Mactaquac Dam, Fredericton Region Museum, Posted on July 17, 2012, available at http://frederictonregionmuseum.wordpress.com/2012/07/17/construction-of-the-mactaquac-dam, Online (retreived 2013).

[30] Bourgoin, S., Disregarded sentiments: discovering the voices of opposition to the Mactaquac Dam, A Thesis Submitted to Saint Mary's University, Halifax, Nova Scotia, in Partial Fulfillment of the Requirements for the Degree of Master's of Arts in History, 129 pp, 2013.

[31] McDonald, J.E. \& Curtis, N.F., Repair and rehabilitation of dams: case studies, US Army Corps of Engineers, Engineer Research and Development Center (Repair, Evaluation, Maintenance, and Rehabilitation Research Program), Technical Report REMR-CS-63, 263 pp, September 1999.

[32] Kidd, S.D., Curry, R.A. \& Munkittrick, K.R., The Saint John River: A State of the Environment Report, Canadian River Institute, University of New Brunswick: Fredericton, Canada, 183 pp., July 2011.

[33] Charlwood, R., Scrivener, K. \& Sims, I., Recent developments in the management of chemical expansion of concrete in dams and hydro projects - Part 1: Existing structures, Hydro 2012, Bilbao, Spain, 17 pp., 2012.

[34] Lunn, R., Google 3D buildings Fredericton (contribution to the Google 3D cities mapping), available at http://www.youtube.com/watch?v=2WqqYFU7y2g, 2012.

[35] Tang, P., Price, R. \& Howe, M., The Saint John River Forecast System - an Integrated Approach, 56th Annual Eastern Snow Conference, Fredericton, NB, Canada, available at http://www.easternsnow.org/meetings/1999/final_program.html, June 2-4, 1999.

[36] Mioc, D., Nickerson, B., Anton, F., Fraser, D., McGillivray, E., Morton, A., Tang, P., Arp, J.P. \& Liang, G., Web-GIS application for flood prediction and monitoring. International Conference on Flood Recovery Innovation and Response, London, WIT 
Transactions on Ecology and the Environment (ISBN: 978-1-84564-132-0), WIT Press, 2008, pp. 145-154. doi: http://dx.doi.org/10.2495/friar080151

[37] Mioc, D., Anton, F., Ahmad, A., Moreiri, K.K., Nikerson, B., McGillivray, E., Mezouaghi, M., Mofford, L. \& Tang, P., Risk maps for evaluation of natural and man-made hazards, risk analysis VIII, C.A. Brebbia (ed.), Wessex Institute of Technology: UK, ISBN: 9781-84564-620-2, eISBN: 978-1-84564-621-9, pp. 552, WIT Transactions on Information and Communication Technologies, 44, 2012. doi: http://dx.doi.org/10.2495/risk120131 